\title{
Prevalence of Substance Use and Associated Factors Among High School Adolescents in Rithepani, Lekhnath-2, kaski, Nepal
}

\author{
Gurung $\mathrm{A}^{1^{*}}$, Shrestha $\mathrm{N}^{1}$, Silwal $\mathrm{M}^{2}$, Gurung $\mathrm{R}^{1}$, Ojha $\mathrm{S}^{3}$ \\ ${ }^{1}$ Lecturer, ${ }^{2} \mathrm{Co}$-ordianator, ${ }^{3}$ Teaching assistant \\ Gandaki Medical College, College of Nursing Sciences, Pokhara, Nepal
}

\begin{abstract}
\begin{tabular}{ll}
\hline ABSTRACT \\
Background: Substance use is a major public health concern in global \\
settings, and is very common during adolescence period leading to \\
physical and/or mental health complications. This study assessed the \\
prevalence of substance use and associated factors among high school \\
adolescents in Rithepani 2, Lekhnath, Kaski, 2073.
\end{tabular}
\end{abstract}
Objectives: The study was designed to provide estimates of substance use by school-going adolescents in Lekhnath and to identify risk factors associated with.

Methods: A school based cross-sectional study was conducted from $17^{\text {th }}$ October to $21^{\text {st }}$ October, 2016 among eighth to $12^{\text {th }}$ grade high school students in the Rithepani-2, Lekhnath. Participants were selected by purposive sampling techniques, and data were collected using questionnaire. Frequency, percentage, means, SD and chi-square test was performed to identify factors associated with substance use.

Results: Majority of the respondents 93 (56.4\%) belonged to the age group 15 - 18 years. Majority of the respondents 88 (53.3\%) were males and $50(30.3 \%)$ were studying in grade 11 . Majority of the respondents $140(84.8 \%)$ were Hindus and 104 (63\%) of the respondents belonged to upper caste group. In terms of education of the respondents' parents, majority of the respondents' mothers $68(41.2 \%)$ had completed their secondary education and similarly, majority of the respondents' fathers $78(47.3 \%)$ had completed their secondary education. Majority of the respondents' mothers 129 (78.2\%) were housewives and majority of the respondents' fathers 48 (29.1\%) were businessmen. Majority of the respondents 136 (82.5\%) belonged to nuclear family and 93 (56.4\%) had per month family income more than Rs 15,000 . Among 165 respondents prevalence of substance use was found to be 10 (6\%).

Regarding the associated factors majority of the respondents 162 (98.2\%) had good relation with their parents, 101 (61.2\%) respondents' family members do not use substance, 128 (77.6\%) respondents reported that substance use was not accepted in their culture. the prevalence of substance use by the respondents is $6.1 \%$ in which five (50\%) respondents consume alcohol, eight (80\%) take cigarette, one (10\%) use tobacco and two (20\%) take ganja. Among the substance users, four $(40 \%)$ reported imitating parents and four $(40 \%)$ reported curiosity as the cause for them to initiate substance use. Regarding the accessibility of the substances among the respondents who use substances, three

Corresponding author

*Gurung A, Lecturer

College of Nursing Sciences

Gandaki Medical College, Pokhara, Nepal 
(30\%) respondents said that it's very difficult whereas one (10\%) said that it's very easy for them to have access to the substances. Majority of the respondents who use substances $6(60 \%)$ avail the substance/s from their friends.

Regarding the Association, there is a significant association between prevalence of substance and substance use by family members with the $\chi^{2}$ value of 7.61 and $p$-value 0.006 which is less than 0.05 significant level. There is also a significant association between the prevalence of substance use and its cultural acceptance with the $\chi^{2}$ value of 4.65 and p-value of 0.031 which is less than 0.05 significant level.

There is a significant association between the prevalence of substance abuse and ethnicity with the $\chi^{2}$ value of 11.81 and with the p-value 0.037 which is less than 0.05 significant level.

Conclusions: The prevalence of substance use among high school adolescent students in selected higher secondary school was found to be $6.1 \%$. There was significant association between prevalence of substances use and cultural acceptance of participants, ethnicity and use of substances by the family members. Based on the findings of the study researcher suggests to initiate awareness and co-ordination program between the school and parents.

\section{INTRODUCTION}

The World Health Organization defines addiction as the state of physiological or psychological addiction to any psychoactive substance; the state is characterized by changes in behavior and other psychological reactions, always including the compulsive need for occasional or regular substance use, guided by the pleasant psychological effect of the substance or avoiding the symptoms of abstinence ${ }^{1}$.

Adolescence is marked by considerable existential conflicts as well as exposure and vulnerability to substance abuse $^{2}$. Young people have greater problems regarding alcohol intake ${ }^{3}$. Moreover, early initiation in alcohol use is one of the most important predictors of future health, socio-cultural and economic problems ${ }^{4}$. The following factors are considered facilitators of alcohol use among adolescents: lifestyle, high levels of stress and anxiety, low self-esteem, depressive symptoms, susceptibility to peer pressure and problems associated with school ${ }^{5}$.

Adolescents are particularly susceptible to involvement in substance use due to the underdeveloped state of the adolescent brain, which can lead to reduced decisionmaking ability and increased long-term effects of drugs and alcohol. Understanding the causes of adolescent substance use is vital for successful prevention and intervention programs.

Data from the National Institute on Drug Abuse (NIDA) and the Centers for Disease Control and Prevention (CDC) reveal high numbers of adolescent substance use in the
United States. Substance use among adolescents can lead to increased risk of transmission of sexually transmitted infections, vehicular fatalities, juvenile delinquency, and other problems associated with physical and mental health.

About 230 million people, or five percent of the world's adult population, are estimated to have used an illegal drug at least once in 2010. Alcohol and other drug (Khat and tobacco) users number about 27 million, which is 0.6 percent of the world adult population. What is more surprising is that, alcohol alone kill around 0.2 million people each year, shattering families and bringing misery to thousands of other people. Similarly, reported that, alcohol and drug use undermines economic and social development and contributes to crime, instability, insecurity and the spread of HIV. Not only that, alcohol and drug abuse is major burdens to society; causing economic costs, health cost, crime-related costs and losses in productivity ${ }^{6}$.

Use of substances such as different alcohols, chewing khat leaves and smoking cigarette has become one of the rising major public health and socio-economic problems worldwide. Recent trends indicate that the use of substances, mainly alcohol, chewing khat and smoking cigarette have dramatically increased particularly in developing countries. Alcohol, especially in high doses, or when combined with khat or tobacco, continues to claim the lives of many people. It is estimated that $9 \%$ of the global population aged 12 or older are classified with 
dependence on psychoactive substances such as alcohol. Heavy consumption of alcohol when shared with chewing khat is associated with many psychological problems including euphoria, hyperactivity, anorexia, insomnia, lethargy and depression. In addition, the combined use of alcohol and khat increase sexual risky behavior contributing to the spread of HIV infection?

The problem of alcohol and drug abuse among College or University students remains an important area of research due to the implications of early substance dependence on the future of the youth ${ }^{8}$.

Alcohol and drug abuse is a common public health risk that peaks in persons between 18 and 25 years of age and is highly prevalent among University and college students. There have been limited studies in developing countries like Nepal ${ }^{9}$.

This study therefore sought to assess the prevalence and factors associated with drug abuse among high school students.

\section{OBJECTIVES}

- To determine the demographic characteristics of participants

- To assess the prevalence of substance use among high school adolescents in Rithepani-2, Lekhnath, Kaski, Nepal

- To explore the prevalence of substance use and associated factors among high school adolescents in Rithepani-2, Lekhnath, Kaski, Nepal

\section{METHODS}

A high school based cross-sectional study was conducted from $17^{\text {th }}$ to $21^{\text {st }}$ October, 2016 amongst $8^{\text {th }}$ to $12^{\text {th }}$ grade high school students in Rithepani-2 Lekhnath, Kaski, Nepal. Participants were selected by purposive sampling techniques, and data were collected using a semi structured questionnaire related to substance use. The study sample was recruited from grade 8 to 12 adolescent students in Triveni Public Higher Secondary School, Rithepani-2, Lekhnath, Kaski, Nepal. Three part structured questionnaire were developed to cover the entire aspects of study.

Part I: This part included demographic characteristics of the participants: Age, gender, religion, ethnicity, education of father and mother, occupation of mother and types of family.
Part II: This part included the associated factors of drug use, like: Economic factors, social factors, family factors, which are the key influencing indicators of substance use.

Part III: It included association between the prevalence of substances use and demographic variables, as well as the prevalence of substances use and the associated factors.

\section{Demographic variables of the respondents}

Table1: Demographic variables of the respondents $(n=165)$

\begin{tabular}{|c|c|c|}
\hline Demographic variables & $\begin{array}{c}\text { Fre- } \\
\text { quency }\end{array}$ & $\begin{array}{c}\text { Percent- } \\
\text { age }\end{array}$ \\
\hline \multicolumn{3}{|l|}{ Age( in years) } \\
\hline$<13$ & 9 & $5.5 \%$ \\
\hline $13-15$ & 52 & $31.5 \%$ \\
\hline $15-18$ & 93 & $56.4 \%$ \\
\hline$>18>18$ & 11 & $6.7 \%$ \\
\hline \multicolumn{3}{|l|}{ Gender } \\
\hline Males & 88 & $53.3 \%$ \\
\hline Females & 77 & $46.7 \%$ \\
\hline \multicolumn{3}{|l|}{ Grade } \\
\hline 8 & 15 & $9.1 \%$ \\
\hline 9 & 31 & $18.8 \%$ \\
\hline 10 & 23 & $13.9 \%$ \\
\hline 11 & 50 & $30.3 \%$ \\
\hline 12 & 46 & $27.9 \%$ \\
\hline \multicolumn{3}{|l|}{ Religion } \\
\hline Hindu & 140 & $84.8 \%$ \\
\hline Christian & 3 & $1.8 \%$ \\
\hline Muslim & 1 & $0.6 \%$ \\
\hline Buddhist & 21 & $12.7 \%$ \\
\hline \multicolumn{3}{|l|}{ Ethnicity } \\
\hline Dalit & 8 & $4.8 \%$ \\
\hline Disadvantaged janjatis & 2 & $1.2 \%$ \\
\hline Disadvantaged non-dalit terai caste group & 1 & $0.6 \%$ \\
\hline Religious minorities & 10 & $6.1 \%$ \\
\hline Relatively advantaged janjatis & 40 & $24.2 \%$ \\
\hline Upper caste group & 104 & $63.0 \%$ \\
\hline \multicolumn{3}{|l|}{ Education of mother } \\
\hline Illiterate & 15 & $9.1 \%$ \\
\hline Primary & 55 & $33.3 \%$ \\
\hline Secondary & 68 & $41.2 \%$ \\
\hline Higher secondary & 19 & $11.5 \%$ \\
\hline Graduate and above & 8 & $4.8 \%$ \\
\hline \multicolumn{3}{|l|}{ Education of father } \\
\hline Illiterate & 8 & $4.8 \%$ \\
\hline Primary & 32 & $19.4 \%$ \\
\hline Secondary & 78 & $47.3 \%$ \\
\hline Higher secondary & 31 & $18.8 \%$ \\
\hline Graduate and above & 16 & $9.7 \%$ \\
\hline
\end{tabular}




\begin{tabular}{lcc}
\hline \multicolumn{1}{c}{ Demographic variables } & $\begin{array}{c}\text { Fre- } \\
\text { quency }\end{array}$ & $\begin{array}{c}\text { Percent- } \\
\text { age }\end{array}$ \\
\hline Occupation of mother & & \\
Housewife & 129 & $78.2 \%$ \\
Service & 3 & $1.8 \%$ \\
Business & 19 & $11.5 \%$ \\
Agriculture & 11 & $6.7 \%$ \\
Others & 3 & $1.8 \%$ \\
Occupation of father & & \\
Self employee & 27 & $16.4 \%$ \\
Service & 19 & $11.5 \%$ \\
Business & 48 & $29.1 \%$ \\
Agriculture & 26 & $15.8 \%$ \\
Others & 45 & $27.3 \%$ \\
Types of family & & \\
Nuclear & 136 & $82.5 \%$ \\
Joint & 24 & $14.5 \%$ \\
Extended & 5 & $3 \%$ \\
Monthly family income & & \\
$\leq 5000$ & 14 & $8.5 \%$ \\
5001 - 10,000 & 23 & $13.9 \%$ \\
10,001 - 15000 & 35 & $21.2 \%$ \\
$\geq 15000$ & 93 & $56.4 \%$ \\
\hline
\end{tabular}

Table 1 shows that majority of the respondents 93 (56.4\%) belonged to the age group of 15 - 18 years. Likewise, majority of the respondents 88 (53.3\%) were males and 50 $(30.3 \%)$ were studying in grade 11 . The table also depicts that majority of the respondents 140 (84.8\%) were Hindus and $104(63 \%)$ of the respondents belonged to upper caste group. In terms of education of the respondents' parents, majority of the respondents' mothers 68 (41.2\%) had completed their secondary education and similarly, majority of the respondents' fathers 78 (47.3\%) had completed their secondary education. Majority of the respondents' mothers 129 (78.2\%) were housewives and majority of the respondents' fathers 48 (29.1\%) were businessmen. Majority of the respondents 136 (82.5\%) belonged to nuclear family and 93 (56.4\%) had family income more than Rs 15,000.

Fig 1: Prevalence of substance use $(n=165)$

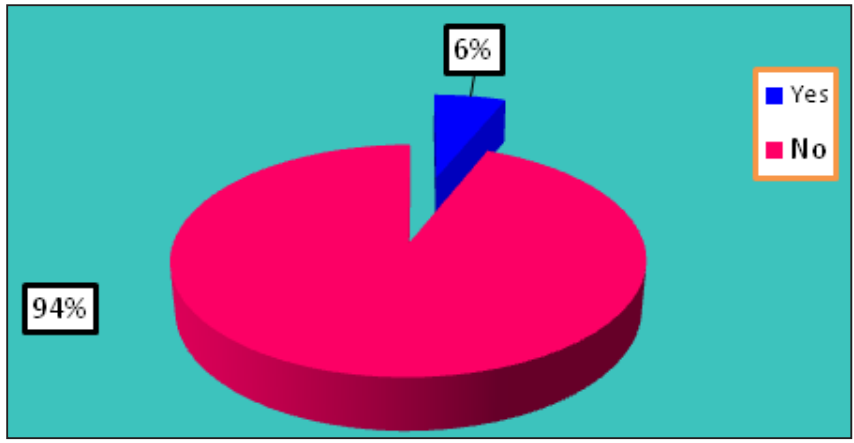

Figure 1 shows that the prevalence of substances use among the respondents was $6 \%$.

\section{Associated factors of substances use among adolescents}

Table 2: Associated factors of substance use among adolescents

\begin{tabular}{|c|c|c|}
\hline Associated factors & $\begin{array}{c}\text { Fre- } \\
\text { quency }\end{array}$ & $\begin{array}{c}\text { Percent- } \\
\text { age }\end{array}$ \\
\hline \multicolumn{3}{|c|}{ Relation with parents } \\
\hline Good & 162 & $98.2 \%$ \\
\hline Poor & 3 & $1.8 \%$ \\
\hline \multicolumn{3}{|c|}{ Substance use by family members } \\
\hline Yes & 64 & $38.8 \%$ \\
\hline No & 101 & $61.2 \%$ \\
\hline \multicolumn{3}{|c|}{ Cultural acceptance of substance use } \\
\hline Yes & 37 & $22.4 \%$ \\
\hline No & 128 & $77.6 \%$ \\
\hline \multicolumn{3}{|c|}{ Types of substances used by the students } \\
\hline Alcohol & 5 & $50 \%$ \\
\hline Cigarette & 8 & $80 \%$ \\
\hline Tobacco & 1 & $10 \%$ \\
\hline Ganja & 2 & $20 \%$ \\
\hline \multicolumn{3}{|c|}{ Cause for initiating the use of substances } \\
\hline Imitating parents & 4 & $40 \%$ \\
\hline Peer pressure & 2 & $20 \%$ \\
\hline Curiosity & 4 & $40 \%$ \\
\hline \multicolumn{3}{|c|}{ Accessibility of substances } \\
\hline Impossible & 2 & $20 \%$ \\
\hline Very difficult & 3 & $30 \%$ \\
\hline Fairly difficult & 2 & $20 \%$ \\
\hline Fairly easy & 2 & $20 \%$ \\
\hline Very easy & 1 & $10 \%$ \\
\hline \multicolumn{3}{|c|}{ Access to the substances } \\
\hline Friends & 6 & $60 \%$ \\
\hline Pocket money & 3 & $30 \%$ \\
\hline Other & 1 & $1 \%$ \\
\hline
\end{tabular}

Table 2 shows that majority of the respondents 162 (98.2\%) had good relation with their parents; 101 (61.2\%) respondents' family members do not use substance, $128(77.6 \%)$ respondents reported that substance use was not accepted in their culture. Fig 1 also shows that the prevalence of substance use by the respondents is $6.1 \%$ in which five $(50 \%)$ respondents consume alcohol, eight $(80 \%)$ take cigarette, one $(10 \%)$ use tobacco and two $(20 \%)$ take ganja. Table 2 shows that among the substance users, four (40\%) reported imitating parents and four (40\%) reported curiosity as the cause for them to initiate substance use. Regarding the accessibility of the substances among the respondents who use substances, three $(30 \%)$ respondents said that it's very difficult 
whereas one $(10 \%)$ said that it's very easy for them to have access to the substances. Table 2 also depicts that the majority of the respondents who use substances 6 $(60 \%)$ avail the substance/s from their friends.

\section{Association between the prevalence of substance abuse and the demographic variables.}

Table 3: Association between the prevalence of substance abuse and the demographic variables

\begin{tabular}{lccc}
\hline Variables & $\chi^{2}$ value & df & p value \\
\hline Grade & 6.82 & 4 & 0.145 \\
Age & 4.99 & 3 & 0.172 \\
Gender & 0.19 & 1 & 0.663 \\
Religion & 7.25 & 3 & 0.064 \\
Ethnicity & 11.81 & 5 & $0.037^{*}$ \\
Education of mother & 6.96 & 4 & 0.138 \\
Education of father & 3.11 & 4 & 0.540 \\
Occupation of mother & 4.40 & 4 & 0.354 \\
Occupation of father & 2.34 & 4 & 0.672 \\
Type of family & 2.27 & 2 & 0.518 \\
\hline
\end{tabular}

*Significant

Table 3 shows that there is a significant association between the prevalence of substance abuse and ethnicity with the $\chi^{2}$ value of 11.81 and with the $p$-value 0.037 which is less than 0.05 level of significance.

\section{Association of the prevalence of substance use and the associated factors}

Table 4: Association between the prevalence of substance use and the associated factors

\begin{tabular}{llll}
\hline Associated factors & $\chi^{2}$ value & df & p-value \\
\hline Monthly family income & 5.42 & 3 & 0.143 \\
$\begin{array}{l}\text { Relation with parents } \\
\begin{array}{l}\text { Substance use by family } \\
\text { members }\end{array}\end{array}$ & 0.19 & 1 & 0.657 \\
$\begin{array}{l}\text { Cultural acceptance of } \\
\text { substance use }\end{array}$ & 4.61 & 1 & $0.006^{*}$ \\
$\begin{array}{l}\text { Difficulty in the access to } \\
\text { substances }\end{array}$ & 3.60 & 4 & 0.463 \\
\hline
\end{tabular}

*Significant

Table 4 shows that there is a significant association between prevalence of substance and the substance use by family members with the $\chi^{2}$ value of 7.61 and $p$-value 0.006 which is less than 0.05 level of significance. There is also a significant association between the prevalence of substance use and its cultural acceptance with the $\chi^{2}$ value of 4.65 and p-value of 0.031 which is less than 0.05 level of significance.

\section{DISCUSSION}

The study was aimed to provide estimates of substance use, and to identify associated factors associated with by school-going adolescents in Rithepani-2, Lekhnath, Kaski, Nepal at selected higher secondary school.

Majority of the respondents 93 (56.4\%) belonged to the age group 15 - 18 years. Likewise, majority of the respondents 88 (53.3\%) were males and 50 (30.3\%) were studying in grade 11 . Majority of the respondents 140 (84.8\%) were Hindus and 104 (63\%) of the respondents belonged to upper caste group. In terms of education of the respondents' parents, majority of the respondents' mothers 68 (41.2\%) had completed their secondary education and similarly, majority of the respondents' fathers 78 (47.3\%) had completed their secondary education. Majority of the respondents' mothers 129 (78.2\%) were housewives and majority of the respondents' fathers 48 (29.1\%) were businessmen. Majority of the respondents 136 (82.5\%) belonged to nuclear family and 93 (56.4\%) had per month family income more than Rs 15,000.

Among the 165 respondents prevalence of substances use was found to be $10(6 \%)$.

Similar study was conducted in Thailand, 2012, to assess the prevalence of alcohol use and associated factors among adolescent students in Thailand. The prevalence was found to be $14.8 \%$.

\section{Associated factors}

Majority of the respondents 162 (98.2\%) had good relation with their parents, 101 (61.2\%) respondents' family members do not use substance, 128 (77.6\%) respondents reported that substance use was not accepted in their culture. the prevalence of substance use by the respondents is $6.1 \%$ in which five $(50 \%)$ respondents consume alcohol, eight (80\%) take cigarette, one (10\%) use tobacco and two (20\%) take ganja. Among the substance users, four (40\%) reported imitating parents and $4(40 \%)$ reported curiosity as the cause for them to initiate substance use. Regarding the accessibility of the substances among the respondents who use substances, three $(30 \%)$ respondents said that it's very difficult whereas one $(10 \%)$ said that it's very easy for them to have access to the substances. Majority of the respondents who use substances six (60\%) avail the substance/s from their friends. 
Similar study was conducted in Thailand, 2012, to assess the prevalence of alcohol use and associated factors among adolescent students in Thailand ${ }^{7}$. Efforts to prevent and control substances use may need to address a cluster of risk behaviors including cigarette smoking, and illicit drug use, easily accessibility of substances, parental behavior to initiate it and friends. A parent school coordination and co-operation could support parents and/ or guardians to become more understanding and caring of their children.

\section{Association between the prevalence of substance use and demographic variables as well as associated factors}

The study found that there was a significant association between prevalence of substance and substance use by family members with the $\chi^{2}$ value of 7.61 and $p$-value 0.006 which is less than 0.05 level of significance. There was also a significant association between the prevalence of substance use and its cultural acceptance with the $\chi^{2}$ value of 4.65 and p-value of 0.031 which is less than 0.05 level of significance. There was a significant association between the prevalence of substance abuse and ethnicity with the $\chi^{2}$ value of 11.81 and with the p-value 0.037 which is less than 0.05 level of significance.

Similar study was conducted in Ethiopia in 2014, to assess the prevalence of substance use and associated factors among high school adolescents ${ }^{8}$. The finding showed that there was significant association between prevalence of substance use and family history of substance use.

\section{CONCLUSIONS}

The prevalence of substance use among high school adolescent students in selected higher secondary school was found to be $6.1 \%$. There was significant association between prevalence of substance use and cultural acceptance of participants, ethnicity and use of substances by the family members. Based on the above findings of the study researcher suggests to initiate awareness and coordination program between the school and parents.

\section{Acknowledgement}

We would like to express our sincere gratitude whole heartedly to Mr. Rajendra Mani Paudel, Principal, Triveni
Public Higher Secondary School, for permitting us to conduct the study and for his support, valuable suggestion and help throughout data collection.

We express our heartfelt thanks to all the participant students who actively participated in the study and for extending their co-operation without which it would have been impossible to conduct the study.

\section{REFERENCES}

1. World Health Organization. International statistical classification of diseases and related health problems - $10^{\text {th }}$ revision. Geneva: WHO; 1992.

2. Strauch ES, Pinheiro RT, Silva RA, Horta BL. Uso de alcohol por adolescents: Estudio de base poblacional. Rev Saude Publica. 2009; 43(4): 647-655.

3. Copeland WE, Angold A, Shanahan L, Dreyfuss J, Dlamini I, Costello EJ. Predicting persistent alcohol problems: A prospective analysis from the great smoky mountain study. Psychol Med. 2012; 42(9): 1925-1935.

4. Marsiglia FF, Ayers S, Gance-Cleveland B, Mettler K, Booth J. Beyond primary prevention of alcohol use: A culturally specific secondary prevention program for Mexican heritage adolescents. Prev Sci . 2011; 13(3): 241-251.

5. Richmond MJ, Merelstein RJ, Metzger A. Heterogeneous friendship affiliation, problem behaviors, and emotional outcomes among high-risk adolescents. Prev Sci. 2012; 13(3): 267-277.

6. UNODC, "World drug report" United Nations publication, New York. 2014; 11-25.

7. WDR, "World drug report" United Nations Office on Drugs and Crime, Vienna. 2012; 10-18.

8. Deressa W, Azazh A. Substance use and its predictors among undergraduate medical students of Addis Ababa University in Ethiopia. BMC Public Health. 2011; 11: 660 .

9. Watson JC. Assessing the potential for alcohol related issues among college student athletes. Online journal. 2002; 4(33): 14-26. 